\title{
Depressive symptoms and drug use among nursing staff professionals
}

\author{
Sintomas depressivos e uso de drogas entre profissionais da equipe de enfermagem \\ Síntomas depresivos y uso de drogas entre profesionales del equipo de enfermería
}

Marcelle Aparecida de Barros Junqueira ${ }^{1}$ (i) Manoel Antônio dos Santos ${ }^{2}$ Lúcio Borges de Araújo ${ }^{1}$ (1) Maria Cristina de Moura Ferreira ${ }^{2}$ Carla Denari Giuliani ${ }^{1}$ Sandra Cristina Pillon ${ }^{2}$

1. Universidade Federal de Uberlândia. Uberlândia, MG, Brasil.

2. Universidade de São Paulo.

Ribeirão Preto, SP, Brasil.
Corresponding authors:

Marcelle Aparecida de Barros Junqueira. E-mail: marcellebarros@ufu.br

Submitted on $04 / 30 / 2018$

Accepted on 06/12/2018.

DOI: 10.1590/2177-9465-EAN-2018-0129

\section{Abstract}

Objectives: To evaluate possible relationships between drug abuse, symptoms suggestive of depression and gender in nursing team professionals. Method: A cross-sectional study conducted in a general hospital with 416 participants. Used questionnaire with sociodemographic information, ASSIST, AUDIT-C and PHQ-2 tests. Used Fisher's Exact Tests, Chi-Square Test, and Multivariate Logistic Regression Analysis. Results: The female gender presented decreased odds ratios for alcohol consumption in the binge pattern and use of marijuana; and double odds ratios for feelings of lack of interest and pleasure. Symptoms suggestive of depression presented potential risks for the use of sedatives. Conclusion: Drug abuse and symptoms of depression are associated and manifest differently, according to gender among nursing staff professionals. Implications for practice: Social and gender roles influence the mental health conditions of these professionals.

Keywords: Nursing; Related Disorders Substance Use; Depression; Occupational Health.

\section{Resumo}

Objetivos: Avaliar possíveis relações entre o abuso de drogas, sintomas sugestivos de depressão e gendero em profissionais da equipe de enfermagem. Método: Estudo com abordagem transversal realizado em hospital geral, com 416 participantes. Usado questionário com informações sociodemográfica, os testes ASSIST, AUDIT-C e PHQ-2. Usados os Testes Exato de Fisher, Teste de Qui-Quadrado, e Análise de Regressão Logística Multivariada. Resultados: O gendero feminino apresentaram razões de chances diminuídas para o consumo de álcool no padrão binge e uso de maconha; e razões de chances dobradas para sentimentos de falta de interesse e prazer. Sintomas sugestivos de depressão apresentaram riscos potenciais para o uso de sedativos. Conclusão: Uso abusivo de drogas e sintomas de depressão estão associados e manifestam-se diferentemente, de acordo com o gendero entre os profissionais da equipe de enfermagem. Implicações para prática: Os papéis sociais e de gendero influenciam nas condições de saúde mental desses profissionais.

Palavras-chave: Enfermagem; Transtornos Relacionados ao Uso de Substâncias; Depressão; Saúde do Trabalhador.

\section{REsumen}

Objetivos: Evaluar posibles relaciones entre el abuso de drogas, síntomas sugestivos de depresión y gendero en profesionales del equipo de enfermería. Método: Estudio con enfoque transversal realizado en hospital general, con 416 participantes. Se utilizó un cuestionario con información sociodemográfica, las pruebas ASSIST, AUDIT-C y PHQ-2. Usados las pruebas exactas de Fisher, Prueba de Qui-Cuadrado, y Análisis de Regresión Logística Multivaria. Resultados: El gendero femenino presentaron razones de posibilidades disminuidas para el consumo de alcohol en el patrón binge y el uso de marihuana; y razones de posibilidades dobladas para sentimientos de falta de interés y placer. Síntomas sugestivos de depresión presentaron riesgos potenciales para el uso de sedantes. Conclusión: Uso abusivo de drogas y síntomas de depresión están asociados y se manifiestan diferentemente, de acuerdo con el gendero entre los profesionales del equipo de enfermería. Implicaciones para la práctica: Los roles sociales y de gendero influyen en las condiciones de salud mental de estos profesionales.

Palabras clave: Enfermería; Trastornos relacionados con sustancias de uso; Depresión; Salud Laboral. 


\section{INTRODUCTION}

Prevalence of the use of psychoactive substances (except alcohol) is of $5,2 \%$ of the world population, which corresponds to 243 million people, being that 27 million had a problematic use of these substances (defined when there is not dependence, but the use causes physical, emocional or social consequences such as involvement with fights, traffic accidents, problems with justice, among others), ${ }^{1}$ beyond that, half of the world population over 15 years old had consumption of acoholic beverages (52\%) and about $3 \%$ of deaths are related to the harmful use of alcohol, specially in youth population. ${ }^{2}$

Problematic consumption has not been differenciated among several groups of the population and, in special, on health professionals category. ${ }^{3}$ Related to nursing staff professionals, rates have varied between 6 and $8 \%,{ }^{3}$ being higher when referred to the abusive use of sedatives (20\%). ${ }^{4}$ Enviornmental factors and those related to work causes, easy access to psychotropics, psychosocial vulnerabilities, work overload and stressful enviornments have contributted significantly to high rates of problems related to alcohol consumption among nursing staff professionals. ${ }^{5}$ Problematic use of psychoactive substances can be associated to several psychiatric illnesses, specially depression. ${ }^{6}$

The development of depressive symptons and it's different levels of gravity have been highlighted among the main causes of psychic sickening of nursing professionals. ${ }^{7,8}$ Worldwide, prevalence of depression is of $7 \%$ in adult population, equivalent to 350 million people. ${ }^{1}$ In 2010, in the world, mental disorders and the use of psychoactive substances were responsible for $7,4 \%$ of all lost years of life, adjusted by incapacity (Disability Adjusted Life Years - DALYs - indicator that measures the effect of mortality and of health problems that affect individual's quality of life), encompassing about 183,6 million people. Depressive disorders were responsible for $40,5 \%$ of DALYs by mental disorders and substance use, being that the use of drugs was responsible for $10,9 \%$ and the use of alcohol for $9,6 \% .^{9}$

Because of these reasons, the relationship between drug use and mental disorders have been evaluated in studies developed with adults and professionals who work in the health area. ${ }^{10}$ In addition, the overlapping of these disorders, also known as double diagnosis or comorbity, have been identified in studies that evaluate mental health of professionals of the nursing staff, ${ }^{7,10}$ which demonstrates the pressing need to know the possible relationships between these two health issues to this population in a more systematized form.

Mental and behavior disorders are responsible for an elevated number of licenses and work absence with the nursing staff, being depression the more frequent disorder. ${ }^{11}$ In addition, this situation becomes even more aggravated when factors related to suicide among nursing professionals are evaluated.
It is verified that depression and the abusive use of alcohol, tabacco and other drugs configurates the main causes of high rates of suicide among health workers. ${ }^{12}$

It is known that prevalence of these comorbities has been differenciated in relation to gender. ${ }^{13,14}$ Globally, women were responsible for more DALYs in all mental and neurological disorders, except for mental disorders in childhood, schizophrenia, substance use disorders, Parkinson's disease and epilepsy. ${ }^{9}$ In spite of that, studies that consider specificities of gender in the nursing context are important, once that certain stressors that interfere in professional exercise practice are related to this variable. If, by one side, male professionals are able to advance on questioning traditional models in relation to gender, by the other, female professionals tend to feel more tired, tense and overloaded; it's highlighted, still, that professional women's mental health is more affected when compared to men. ${ }^{15}$

Such grounds justifies the relevance of the present study, because when evaluating professional's mental health of a nursing staff individual pecularities and gender should be considered, which rises as a very important personal determinant for triggering health issues. In addition, on the literature studies are still incipient, once few investigations have evaluated associations between depression and abusive drug use among professionals from the nursing staff, and either have considered the influence of gender. ${ }^{15}$ Nursing professionals are present in pratically all stabilishments of health services in Brazil and in the world, representing a great contingent of the work force, dealing with direct and indirect cares of individuals, families and communities; health promotion for the nursing worker interests socially because it impacts directly in the population's quality of care. In that sense, this study aimed to compare possible relationships among abusive drug use, depressive symptons and gender in professionals from the nursing staff.

\section{METHOD}

It's a cross sectional study with quantitative approach. The study was developed between the months of June and August 2016, with professionals from the nursing staff of a big general hospital in the state of Minas Gerais, Brazil. In the moment of the data collection, the hospital nursing staff was composed by 1214 workers. A prevalence of $50 \%$ od abusive alcohol use and other drugs was considered, ${ }^{1,2}$ an acceptable error of $5 \%$ and a confidence of $95 \%$, totalizing 402 professionals considering probable sampling at random; but all professionals were invited for the research and, at the end of it, 416 workers accepted to participate in the study.

Eligibility criteria to participate in the research were: being 18 or over, be a worker (nursing assistant, nursing technician or nurse) hired by the hospital. Visits were developed in all sectors of the hospital and in different days and hours to publicize the 
study, offering necessary clarifications and inviting to participate in the research. Professionals were approached in rest breaks, when the instrument for data collection and two copies of the Free and Clarified Consent Form (FCCF) was delivered for those who accepted to participate in the study voluntarily.

The questionnaire used was composed of: a) sociodemographic and work information. b) Alcohol Use Disorder Identification Test - Consumption (AUDIT-C), an instrument composed by three items that evaluate the quantitity and frequency of alcohol consumption. It's final classification present levels of consumption in terms of risk or abusive use, also known as binge use or binge episode, that is, when four or more doses of alcoholic beverage is consumed in a timeframe of less than 2 hours. ${ }^{16} \mathrm{~A}$ term we will also use in the present study is the problematic use. c) Alcohol, Smoking and Substance Involvement Screening Test (ASSIST), questionnaire composed of eight questions, used to screen the level of use of alcohol, tobacco and other psychoactive substances. ${ }^{17}$ d) Patient Health Questionnaire-2 (PHQ-2), instrument composed by two items that approach the main suggestive symptoms for depression according DSM-IV. ${ }^{18} \mathrm{All}$ instruments applied were validated for the brazilian population and presented good levels of confidentiality for it's usage. The study was approved by Research Ethics Committee from the Federal University of Uberlândia (Protocolo CAAE: 47651315.4.0000.5152). All participants signed Free and Clarified Consent Form. The study followed the ethical assumptions defined by the Resolution 466/2012.

For statistical analysis, a data base was created on the Statistical Program of Social Science (SPSS) version 20, for Windows. Descriptive analysis were developed, which the results will be presented with absolute frequency ( $\mathrm{n}$ ) and percentage (\%). Bivaried analysis of data were developed Exact Test of Fisher and Chi-Square Test $\left(\mathrm{X}^{2}\right)$ to compare categoric variables. Also multivariate logistic regression analysis was used, which the results will be presented in function of odds ratio. Two models were tested, considering independent variables: a) suggestive sign for depression and $b$ ) gender (coding in female equals 1 and male equals 0 ), controlled by dependent variables (outcome): drug use such as alcohol, tabacco, marijuana, sedatives, cocaine, crack, amphetamines, opioids, inhalants, hallucinogens and others. The level of significance was set at $5 \%$ for all tests.

\section{RESULTS}

Sample was composed by 416 nursing professionals; being $115(28,5 \%)$ nursing assistants, $199(49,3 \%)$ nursing technicians and $90(22,3 \%)$ nurses. Female predominance $350(84,1 \%)$, adults with average of age 41,2 years old, varied of 20 and 67 years old, $282(69,5 \%)$ married and adherents of the Catholic religion 177 (44,1\%) was observed.
The drugs most consumed at medium/high risk level were alcohol in the binge standard $(35,8 \%)$, alcohol $(21,2 \%)$ and tabacco $(6,6 \%)$, data available on Table 1 . The presence of inhalant and injecting drug users was not observed, remembering that these possibilities were not considered as exclusion criteria. Male was characterized by a predominance of alcohol consumption in binge $\left(52,5 \%\right.$ male versus $32,9 \%$ female $\chi^{2}(1)$ $=8,688 p=0,003)$ and marijuana use $(7,3 \%$ male versus $1,4 \%$ female $\chi^{2}(1)=6,630 p=0,010$ ).

From the total, $21,3 \%$ presented suggestive symptoms for depression. Female professionals presented higher frequency as for having low interest or pleasure to do things (female, $6 \%$ versus $11,1 \%$ male $\chi^{2}(1)=4,202 p=0,040$ ) and suggestive sings for depression (female $22,9 \%$ versus $11,7 \%$ male $\chi^{2}(1)=3,434$ $p=0,042$ ), when compared with male Table 2 .

In the final logistic regression model (Table 3), it is possible to observe that female professionals from the nursing staff present low odds ratio of alcohol beverage binge consumption ( $56 \%$ or OR 0,44 [IC95\% 0,26-0,77]; $p=0,003$ ) and of using marijuana in medium/high risk level in comparison with male professionals (81\% - OR 0,19 [IC95\% 0,05-0,77]; $p=0,020)$. However, the women showed a double chance of showing feelings of disinterest and lack of pleasure in relation to men (OR 2,47 [IC95\% 1,02-5,99]; $p=0,046$ ).

Table 4 presents the comparison between depression symptoms and risk level to drug use. It is possible to notice the predominance of sedative use among professionals with suggestive symptoms for depression $(57,1 \%$ yes versus $42,9 \%$ no $p=$ $0,035)$. The table also shows that professionals with suggestive symptoms for depression presented potentially increased risks for sedative use (OR 5,40 [IC95\% 1,17-24,80]; $p=0,035$ ). For the other drugs, there was no statistical significance.

\section{DISCUSSION}

Sociodemographical and professional profile of the participants of the present study was predominantly married, catholic women with previous training as nursing assistant or technician. These results corroborate with findings of another national study that found predominant distribution of women, nursing technicians and assistants. ${ }^{19}$ The presence of female among professionals from the nursing staff have gradually decreasing throughout the years, however, it still represents the majoritiy. ${ }^{19}$ Such characteristic cannot be ignored because if by one side it's rooted in the historic bases of the profession, on the other, it influences the Nursing modus operandi nowadays, once the professional acting is consitututed by people inserted in a determined sócio-historical and cultural context; consequently, susceptibility to drug use and depression is forged in this context. 
Table 1. Distribution of nursing staff in a general hospital, according to the risk level of drug use and gender $(\mathrm{N}=416)$, Uberlândia-MG, Brazil, 2016.

\begin{tabular}{|c|c|c|c|c|c|c|c|c|}
\hline \multirow{2}{*}{ Drugs Risk Level } & & \multicolumn{2}{|c|}{ Female } & \multicolumn{2}{|c|}{ Male } & \multicolumn{2}{|c|}{ Total } & \multirow{2}{*}{$\mathrm{p}^{*}$ value } \\
\hline & & $\mathbf{n}$ & $\%$ & $\mathbf{n}$ & $\%$ & $\mathbf{n}$ & $\%$ & \\
\hline \multirow{2}{*}{ Alcohol (binge) } & Abstemious/Low & 235 & 67,1 & 29 & 47,5 & 264 & 64,2 & \multirow{2}{*}{$0,003^{*}$} \\
\hline & Medium/High & 115 & 32,9 & 32 & 52,5 & 147 & 35,8 & \\
\hline \multirow{2}{*}{ Alcohol } & Abstemious/Low & 276 & 78,9 & 48 & 78,7 & 324 & 78,8 & \multirow{2}{*}{0,976} \\
\hline & Medium/High & 74 & 21,1 & 13 & 21,1 & 87 & 21,2 & \\
\hline \multirow{2}{*}{ Tabacco } & Abstemious/Low & 261 & 93,9 & 52 & 91,2 & 313 & 93,4 & \multirow{2}{*}{0,461} \\
\hline & Medium/High & 17 & 6,1 & 5 & 8,8 & 22 & 6,6 & \\
\hline \multirow{2}{*}{ Marijuana } & Abstemious/Low & 273 & 98,6 & 51 & 92,7 & 324 & 97,6 & \multirow{2}{*}{$0,010^{*}$} \\
\hline & Medium/High & 4 & 1,4 & 4 & 7,3 & 8 & 2,4 & \\
\hline \multirow{2}{*}{ Sedative } & Abstemious/Low & 267 & 97,4 & 54 & 100 & 321 & 97,9 & \multirow{2}{*}{0,235} \\
\hline & Medium/High & 7 & 2,6 & - & - & 7 & 2,1 & \\
\hline \multirow{2}{*}{ Cocaine, Crack } & Abstemious/Low & 275 & 99,3 & 55 & 100 & 330 & 2 & \multirow{2}{*}{0,527} \\
\hline & Medium/High & 2 & 0,7 & - & - & 2 & 0,6 & \\
\hline \multirow{2}{*}{ Amphetamines } & Abstemious/Low & 275 & 99,6 & 56 & 100 & 331 & 99,7 & \multirow{2}{*}{0,204} \\
\hline & Medium/High & 1 & 0,4 & - & - & 1 & 0,3 & \\
\hline \multirow{2}{*}{ Opioids } & Abstemious/Low & 272 & 2 & 53 & 100 & 327 & 99,1 & \multirow{2}{*}{0,745} \\
\hline & Medium/High & 3 & 1,1 & - & - & 2 & 0,9 & \\
\hline \multirow{2}{*}{ Others } & Abstemious/Low & 267 & 98,9 & 52 & 100 & 322 & 99,1 & \multirow{2}{*}{0,747} \\
\hline & Medium/High & 3 & 1,1 & - & - & 3 & 0,9 & \\
\hline
\end{tabular}

* Chi-Square Test $\left(\chi^{2}\right)$. Value of $p<0,05$.

Table 2. Distribution of nursing staff in a general hospital, according to suggestive symptoms for depression and gender ( $\mathrm{N}=416)$, Uberlândia-MG, Brasil, 2016.

\begin{tabular}{llccccccc}
\hline \multirow{2}{*}{ Suggestive Symptoms for Depression } & \multicolumn{2}{c}{ Female } & \multicolumn{2}{c}{ Male } & \multicolumn{2}{c}{ Total } & p* \\
& & $\mathbf{n}$ & $\mathbf{\%}$ & $\mathbf{n}$ & $\mathbf{\%}$ & $\mathbf{n}$ & $\mathbf{\%}$ & value \\
\hline Low interest or pleasure & No time or various days & 240 & 76,4 & 48 & 88,9 & 288 & 78,3 & 0,040 \\
to do things & More than half or almost every day & 74 & 23,6 & 6 & 11,1 & 80 & 21,7 & \\
Feeling sad, depressed & No time or various days & 257 & 81,3 & 47 & 90,4 & 304 & 82,6 & 0,110 \\
and without hope & More than half or almost every day & 59 & 18,7 & 5 & 9,6 & 64 & 17,4 & \\
Suggestive signs for & No & 233 & 77,1 & 46 & 88,5 & 285 & 78,7 & 0,042 \\
depression & Yes & 71 & 22,9 & 6 & 11,7 & 77 & 21,3 & \\
\hline
\end{tabular}

* Chi-Square Test $\left(\chi^{2}\right)$. Value of $p<0,05$.

In that sense, it seems fundamental to know the mental health conditioners of professionals from the nursing staff, being the drug consumption and vulnerability to depression two important indicators, by epidemiological dimension of these issues have gaining from the point of view of global health. ${ }^{1,9} \mathrm{~A}$ study showed that there are different risk factors for substance abuse among professionals from the nursing staff, among them are psychiatric factors, which include the presence of depression and demographical factors, specially the gender issue. ${ }^{20}$
On the present sample, $35,8 \%$ consumed alcoholic beverages in a binge pattern and $21,2 \%$ had an abusive use of alcohol or have a probable dependency. It was also observed that $6,6 \%$ of participants were active. These indices show that the problematic use of psychoactive substances by health professionals does not differ from the general population. Evidence show high rates of substance abuse among nursing professionals. ${ }^{1-5}$ This phenomenon catches the attention, once that the sample of the present study is constituted by health professionals, category which, by 
Table 3. Logistic regression model for drug use and depression, considering gender as a predictive variable $(\mathrm{N}=416)$, Uberlândia-MG, Brasil, 2016.

\begin{tabular}{lccc}
\hline & OR adjusted & Cl95\% & p* value \\
\hline Drugs & & & \\
\hline Alcohol (binge) & 0,44 & $0,26-0,77$ & 0,003 \\
Alcohol & 1,17 & $0,88-1,55$ & 0,286 \\
Tabacco & 0,68 & $0,24-1,93$ & 0,463 \\
Marijuana & 0,19 & $0,05-0,77$ & 0,020 \\
\hline Suggestive Symptoms for Depression & & & \\
\hline Have low interest or pleasure to do things & 2,47 & $1,02-5,99$ & 0,046 \\
Feeling sad, depressed and without hope & 2,16 & $0,82-5,66$ & 0,118 \\
Suggestive for Depression & 2,28 & $0,93-5,55$ & 0,070 \\
\hline
\end{tabular}

* Chi-Square Test $\left(\chi^{2}\right)$. Value of $p<0,05$.

Table 4. Comparison between drug use and depression symptoms and model of logistic regression for drug use, considering suggestive symptoms for depression as predictive variable among professionals from a nursing staff of a general hospital ( $\mathrm{N}=416)$, Uberlândia-MG, Brazil, 2016.

\begin{tabular}{|c|c|c|c|c|c|c|c|c|c|c|}
\hline \multirow{3}{*}{$\begin{array}{l}\text { Drug use } \\
\text { (medium or high risk) }\end{array}$} & \multicolumn{7}{|c|}{ Suggestive Symptoms for Depression } & \multirow{2}{*}{\multicolumn{3}{|c|}{ Logistic regression model }} \\
\hline & \multicolumn{2}{|c|}{ Yes } & \multicolumn{2}{|c|}{ No } & \multicolumn{2}{|c|}{ Total } & \multirow{2}{*}{ p* value } & & & \\
\hline & $\mathbf{n}$ & $\%$ & $\mathbf{n}$ & $\%$ & $\mathbf{n}$ & $\%$ & & OR & $\mathrm{Cl} 95 \%$ & $\mathrm{p}^{* *}$ value \\
\hline Alcohol (binge) & 27 & 22,1 & 95 & 77,9 & 122 & 100 & 0,787 & 1,08 & $0,63-1,83$ & 0,772 \\
\hline Alcohol & 18 & 26,9 & 49 & 73,1 & 67 & 100 & 0,467 & 1,13 & $0,89-1,43$ & 0,296 \\
\hline Tabacco & 6 & 28,6 & 15 & 71,4 & 22 & 100 & 0,409 & 1,53 & $0,57-4,12$ & 0,398 \\
\hline Marijuana & 1 & 14,3 & 6 & 85,7 & 7 & 100 & 1,000 & 0,62 & $0,73-5,25$ & 0,663 \\
\hline Sedative & 4 & 57,1 & 3 & 42,9 & 7 & 100 & 0,035 & 5,40 & $1,17-24,80$ & 0,030 \\
\hline Opioids & - & - & 2 & 100 & 2 & 100 & 1,00 & 3,44 & $0,47-25,21$ & 0,223 \\
\hline Cocaine, Crack & 2 & 100 & - & - & 2 & 100 & 0,211 & 2,34 & $0,37-22,36$ & 0,244 \\
\hline Others & - & - & 03 & 100 & 3 & 100 & 1,00 & 2,44 & $0,46-12,73$ & 0,289 \\
\hline
\end{tabular}

* Exact Test of Fisher. ${ }^{* *}$ Chi-Square Test $\left(\chi^{2}\right)$. Note: alcohol, tobacco, marijuana, sedatives, cocaine, crack, amphetamines, opioids, inhalants, hallucinogens and others were controlled by the variable suggestive symptoms for depression.

educational investments that received throughout the process of training, detain qualified information about possible harmful consequences occured by abusive use of alcohol and tabacco. Therefore, hypothetically, consumption was expected to be much lower in this group of professionals. This way, it is perceived the urgent need for educational investments and preventive efforts directed specifically to the professionals of the nursing team, in a perspective of integral care of these subjects, so that one can go beyond technical and scientific knowledge, incorporating the social dimensions, emotional, cultural and work organization.

Beyond that, studies ${ }^{3-5,8,11,12,24,26,29}$ suggest that work envirornments in which nursing workers are frequently exposed, and present inadequate ergonomic conditions, long and stressful work and workloads, lack of psychosocial support to deal with the complexity of the health-disease-care process, and/or death, may contribute to the problematic use of alcohol or other drugs.
As for drug use, men presented predominance of binge alcohol consumption and marijuana use. These data were confirmed on multivaried analysis, showing that women presented a low risk of binge alcohol consumption and marijuana use. These results were also reported in studies of population base. ${ }^{1,2,21}$ In this direction, other researches showed social and cultural characteristics related to the act of drinking and manhood - such, for exemple, one's higher tolerance, social and family acceptance in male individuals, end up reinforcing even more the alcohol consumption among men. ${ }^{22,23}$ Binge alcohol use was observed, predominantly, among men, in study with 876 participants of the metropolitan region of São Paulo. In this group, 48,4\% admitted that consumed alcohol, at least once in drunkenness pattern in the last year, being that, among women, these percentage was of $18,1 \%{ }^{22}$ Still in relation to alcohol use, a study with professionals of brazilian nursing staff identified a higher prevalence of 
consumption among men, even though differences in relation to women are decreasing. ${ }^{5}$ In Canada, an inquiry developed online with 4064 nurses showed that $9,4 \%$ of men and $5,8 \%$ of women consumed alcoholic beverages in abusive levels. ${ }^{24}$

Studies that evaluated the expectations related to alcohol use among men showed that they are diverse and that, many times, are associated to the search of anxiety control, disinhibition to address intimate aspects in interpersonal relationships, increase of genderuality and reduction of tension levels. Men also presented negative expectations, such as more disinhibited expression of aggressiveness and reduction of condoms use in general relationships. This way, it's perceived thst social context is a determinant factor on the profile for alcohol consumption pattern. 22,23

In the present study, $1,4 \%$ of women and $7,3 \%$ of men had medium/high risk for marijuana use and, in the logistic regression mode, women presented lower odds ratio of use compared to men. WHO estimates that about 181 million people use marijuana as a recreational form in the world, being that the prevelance changes according to geographical region. ${ }^{25}$ In Brazil, the prevalence of dependence reaches $1 \%$ of the population, and men make three times more use than women. ${ }^{21}$ Studies on marijuana use among health professionals are still scarce. A survey conducted in Brazil with 266 undergraduate nursing students showed that $8.6 \%$ of students reported using marijuana in the last year. ${ }^{26}$

Literature points out that general male roles and social norms are predictors for alcoholic intoxication and marijuana use, specially in adolescence. ${ }^{27} \mathrm{~A}$ proposed hypothesis is that, biologically, women have a reduced risk for the use of these substances because of physical vulnerability to adverse effects from consumption. In addition, excessive use of alcohol and marijuana among men during adolescence tends to remain, or even increase, in adult life. A relationship between marijuana use and problem alcohol use was also identified. ${ }^{28}$ Thus, in the professionals of the nursing team, the profile of psychoactive substance abuse seems to manifest differently between the male and female genderes. Women tend to get sick, even physically, faster and more severely. They tend to seek help for symptoms associated with drug abuse, such as insomnia, stress, anxiety, and depression, with higher rates of comorbidities. ${ }^{20}$

The underreporting of drug abuse cases is also more common among the professionals from the nursing staff of the female gender. Generally, women that abuse of drugs tend to start treatment due to consequences from physical, mental or family problems, while that men tend to be identified more precociously and sent to specialized services. ${ }^{20}$ Thus, it is perceived that professionals from the nursing staff are not immune to drug abuse and present a risk pattern for binge drinking and marijuana use, similar to that found in the general population. Many times, this issue is overestimated by supervisors and employers of these professionals and even by their peers, that end up making an early detection. Substance abuse can be associated to inadequate work conditions, directly impacting on the increase in work accidents, illness, absenteeism, withdrawal and disability. ${ }^{29}$

Of professionals investigated in the present study $21,3 \%$ presented suggestive symptoms for depression. This rate is very superior than the one presented in the National Health Research (NHR) 2013, that found 7,6\% of adults self-report symptoms of depression. ${ }^{14} \mathrm{~A}$ Brazilian study developed with 266 nursing technicians and assistants identified that $15,5 \%$ of professionals presented suggestive symptoms for depression..$^{30}$ In inernational studies, it's noticed a variability of prevalence of suggestive symptoms for depression among nurses, being $13 \%$ in Australia ${ }^{31}$ and $38 \%$ in China. ${ }^{32}$ These results present a worrying scenario of of susceptibility to symptoms of depression among nursing professionals, once that results are superior than the ones found in general adult population. Studies ${ }^{7,8}$ that depression in nursing professionals is associated with suicide risk, the main factors related to the work envirornment with high work load, lack of autonomy and interpersonal conflicts.

Still in relation to depression, the present research evidenced that women act on nursing present a domain of suggestive symptoms for depression, with lack of interest or pleasure to do things, having double risk to present these feelings. A study with populational comprehensiveness showed that $10,9 \%$ of women report medical diagnosis of depression, being that among men this rate was of $3,9 \% .{ }^{14} \mathrm{~A}$ research conducted with 94 nurses showed positive association between the predominance of depression and the female gender. ${ }^{33}$ Som possible explainations for the development of depression in women are related to genetic issues and hormonal regulation, menstrual cycle and pregnancy-puerperal, family relationship patterns and change in it's social and cultural role. ${ }^{34}$

The lack of interest of pleasure to do things, found significally on women, can hold a relationship, among other factors, with the fact that female professionals from the nursing staff, in their few time off, frequently have few or almost no time to care for themselves, or to dedicate to hobbies or activities of personal interest, being that leisure many times is limited to sleeping or praying..$^{35}$ Beyond that, these workers are predisposed to double journey of work, having to reconcile paid activities with home work, caring for children and eventual partner difficulties for spending many hours away from home..$^{15,35}$

A study of work-related dislocations due to Common Mental Disorders (CMD) showed a predominance of $76.3 \%$ of female nursing professionals, with Depressive Episodes being the most frequent cause, with $52.7 \%$ of the cases. ${ }^{36}$ These data suggest that inequality on gender relations also have repercussion on the 
mental health condition, including the vulnerability to depression on nursing professionals. Suggestive symptoms for depression were predominant among professionals that used sedatives. It was also observed that the odds ratio of potentially raised abuse in this group. It's important to consider that sedatives, in this case, is referred to psychopharmaceuticals without medical prescription. In a study conducted in Brazil with 657 subjects from a public university, involving teachers, employees and students, associations were also found between depressive symptoms and use of benzodiazepines. ${ }^{10}$

This is a very worrisome issue in the nursing context, considering the involvement, the easiness of access of this medicines and alarming rates of use by professionals. A research showed that $6,1 \%$ of 49 nursing professionals of an Intensive Care Unit (ICU) used benzodiazepines and $4 \%$ used pain killers, being that only $24,4 \%$ the use of medicine was prescribed. ${ }^{37}$ In the United States of America (USA), of 2439 resident nurses evaluated anesthesiology programs, it was observed that benzodiazepines were the third highest drug abuse among professionals. ${ }^{38}$

Again, the use of psychotropic substances, as well as depression, in the nursing work routine may be related to working conditions, difficulties in dealing with suffering and death, interpersonal and interprofessional relations and professional unpreparation. The consumption of these substances aims to reduce the physical and mental loads to which these professionals are continuously exposed. ${ }^{39}$ The abusive use of sedatives should be seriously investigated in nursing, considering the particularity of the large contingent of female gendero professionals and that it is the only class of psychoactive substances in which the rate of consumption among women is higher when compared to men. In addition, female gendero professionals are at increased risk for the development of dependence of this drug. ${ }^{40}$

The present study presents limitations in the sense that it has been performed with a sample of professionals from the nursing team of only one health institution and for convenience, which may restrict the generalization power of the results. We also did not analyze the differences between the age, position and sector of these professionals and their satisfaction with the work, variables that may influence the levels of substance use and depression symptoms of health workers. Another point to consider is the low frequency of self reports about abusive use of some drugs (marijuana, sedatives, cocaine, crack, opiodis and others) can introduce a bias on results, specially on confidance intervals (Cl).

Results found can contribute to clinical practice in a sense of put in relief the need to evaluate aspects related to the use of psychoactive substances and in the occurance of suggestive symptoms for depression among nursing professionals and other health professionals. Findings show that this evaluation can not be done in a homogeneous form, but considering also the issue of differences between genders, once there were diverge results between men and women. It is necessary to broaden the view beyond the technical-professional profile of the worker, also considering their personal demands, and to understand that, in addition to working conditions, the social and gender roles influence the mental health conditions of these professionals. Finally, it's highlighted the originality of the study, which evaluates the occurance of these phenomena from a difference perspective between men and women, on seeking associating drug use and depression in professionals from the nursing staff among health male and female workers. Other studies are necessary in different scenarios of attention of geographical regions in order to comprehend the Best influence of these contexts in associating suggestuve symptoms for depression and the drug use, and differences between both male and female professionals.

\section{CONCLUSION}

It is concluded that there were association among suggestive signs for depression and female nursing professionals, with odds ratio raised to feelings of lack of interest or pleasure in these women. It was also verified that male professionals presented higher odds ratio to risk of binge alcohol use and marijuana use. The use of sedatives associated with feelings of hopelessness and sadness, as well as lack of interest and pleasure, being observed a higher risk for it's use in individuals with suggestive signs for depression.

Therefore, it's important to consider that characteristics such as gender of the nursing professional must be considered to elaborate administration strategies to promote worker's health, in special on what considers prevention to misuse of psychotropics and depression. Other possibilities for research are opened from the results found, for example if there is difference in relation to the gendero of nursing professionals or related area in symptoms of other mental disorders; or if other sociodemographic characteristics such as occupational category or age influence the use of psychoactive substances or the appearance of symptoms of mental transtono.

\section{REFERENCES}

1. United Nations Office on Drugs and Crime - UNODC. World Drug Report 2014. Vienna: UNODC: 2014. [cited 2017 Jun 17]. Available from: https://www.unodc.org/documents/data-and-analysis/WDR2014/ World_Drug_Report_2014_web.pdf

2. World Health Organization - WHO. Global status report on alcohol and health 2014. Geneva: World Health Organization; 2014. [cited 2017 Jun 17]. Available from: http://www.who.int/entity/substance_abuse/ publications/global_alcohol_report/msbgsruprofiles.pdf?ua=1

3. Kunik D. Substance use disorders among registered nurses: prevalence, risks and perceptions in a disciplinary jurisdiction. J Nurs Manag [Internet]. 2015 Jan; [cited 2017 Jun 17]; 23(1):54-64. Available from: http://onlinelibrary.wiley.com/doi/10.1111/jonm.12081/pdf. DOI: 10.1111/jonm.1208 
4. Monroe T, Kenaga H. Don't ask don't tell: substance abuse and addiction among nurses. J Nurs Manag [Internet]. 2010 Feb; [cited 2017 Jun 17]; 20(3-4):504-9. Available from: https://www.ncbi.nlm.nih.gov/ pubmed/21040041. DOI: 10.1111/j.1365-2702.2010.03518.x

5. Oliveira EB, Fabri JMG, Paula GS, Souza SRC, Silveira WG, Silva Matos G. Patterns of alcohol use among nursing workers, and its association with their work. Rev Enferm UERJ [Internet]. 2013 Dec; [cited 2017 Jun 17]; 21(6):729-35. Available from: http://www.e-publicacoes.uerj. br/index.php/enfermagemuerj/article/view/11514. DOI: 10.12957/ reuerj.2013.11514

6. Leal EM, Delgado PGG, Mann R, Strike C, Brands B, Khenti A. Comorbidity study: psychic suffering and drug abuse in people in treatment centers, Macaé - Brazil. Macaé, Brasil. Texto Contexto Enferm [Internet]. 2012; [cited 2017 Jun 17]; 21(no.esp):96104. Available from: http://www.scielo.br/scielo.php?script=sci arttext\&pid=S0104-07072012000500013\&Ing=en. DOI: 10.1590/ S0104-07072012000500013

7. Ferreira LAL, Ferreira LL. Depression in nursing work: a systematic review. Univer Ciênc Saúde [Internet]. 2015 Jan/Jun; [cited 2017 Jun 17]; 13(1):41-8. Available from: https://www.publicacoes.uniceub.br/ cienciasaude/article/view/2849. DOI: 10.5102/ucs.v13i1.2849

8. Silva DSD, Tavares NVS, Alexandre ARG, Freitas DA, Brêda MZ, Albuquerque MCS, et al. Depression and suicide risk among nursing professionals: an integrative review. Rev Esc Enferm USP [Internet]. 2015 Dec; [cited 2017 Jun 17]; 49(6):1023-31. Available from: http://www.scielo.br/scielo.php?script=sci_art text\&pid=S0080-62342015000601023. DOI: $10.1590 /$ S0080623420150000600020

9. Whiteford HA, Ferrari AJ, Degenhardt L, Feigin V, Vos T. The global burden of mental, neurological and substance use disorders: an analysis from the Global Burden of Disease Study 2010. PLoS ONE [Internet]. 2015; [cited 2017 Jun 17]; 10(2):e0116820. Available from: https://www.ncbi.nlm.nih.gov/pmc/articles/PMC4320057/. DOI: 10.1371/journal.pone. 0116820

10. Horta LR, Horta BL, Horta CL. Substances use and minor psychiatric disorders in a university in the South of Brazil. Psicol Rev [Internet] 2012 Aug; [cited 2017 Jun 17]; 18(2):264-76. Available from: http://periodicos. pucminas.br/index.php/psicologiaemrevista/article/view/P.16789563.2012v18n2p264. DOI: 10.5752/P.1678-9563.2012v18n2p264

11. Santana LL, Sarquis LMM, Miranda FMA, Kalinke LP, Felli VEA, Miniel VA. Health indicators of workers of the hospital area. Rev Bras Enferm [Internet]. 2016 Jan/Feb; [cited 2017 Jun 17]; 69(1):30-9. Available from: http://www.scielo.br/scielo.php?script=sci_arttext\&pid =S0034-71672016000100030. DOI: 10.1590/0034-7167.2016690104i

12. Alderson M, Parent-Rocheleau X, Mishara B. Critical review on suicide among nurses. What about work-related factors? Crisis [Internet]. 2015; [cited 2017 Jun 17]; 36(2):91-101. Available from: https://www.ncbi.nIm. nih.gov/pubmed/25708252. DOI: 10.1027/0227-5910/a000305

13. Fattore L, Melis M, Fadda P, Fratta W. Gender differences in addictive disorders. Front Neuroendocrinol [Internet]. 2014 Aug; [cited 2017 Jun 17]; 35(3):272-84. Available from: https://www.ncbi.nlm.nih.gov/ pubmed/24769267. DOI: 10.1016/j.yfrne.2014.04.003

14. Stoppa SR, Malta DC, Oliveira MM, Lopes CS, Menezes PR, Kinoshita RT.Prevalence of self-reported depression in Brazil:2013 National Health Survey results. Rev Bras Epidemiol [Internet]. 2015 Dec; [cited 2017 Jun 17]; 18(Suppl.2):170-80. Available from: http://www.scielo.br/scielo. php?script=sci_arttext\&pid=S1415-790X2015000600170\&lng=en. DOI: $10.1590 / 1980-5497201500060015$

15. Pereira AV. Nurses' daily life: gender relations from the time spent in hospital. Rev Latino Am. Enferm [Internet]. 2015 Sep/Oct; [cited 2017 Jun 17]; 23(5):945-53. Available from: http://www.scielo.br/ scielo.php?script=sci_arttext\&pid=S0104-11692015000500945. DOI: 10.1590/0104-1169.0485.2635

16. García Carretero M, Novalbos Ruiz J, Martínez Delgado J, O'Ferrall González C. Validación del test para la identificación de trastornos por uso de alcohol en población universitaria: AUDIT y AUDIT-C. Adicciones [Internet]. 2016; [cited 2017 Jun 17]; 28(4):194-204. Available from: http://www.adicciones.es/index.php/adicciones/article/view/775. DOI: 10.20882/adicciones. 775
17. Henrique IFS, De Micheli D, Lacerda RB, Lacerda LA, Formigoni MLOS. Validation of the Brazilian version of Alcohol, Smoking and Substance Involvement Screening Test (ASSIST). Rev Assoc Med Bras [Internet]. 2004 Jan/Apr; [cited 2017 Jun 17]; 50(2):199206. Available from: http://www.scielo.br/scielo.php?script=sci_ arttext\&pid=S0104-42302004000200039\&lng=en. DOI: $10.1590 /$ S0104-42302004000200039

18. Arroll B, Goodyear-Smith F, Crengle S, Gunn J, Kerse N, Fishman T, et al. Validation of PHQ-2 and PHQ-9 to screen for major depression in the primary care population. Ann Fam Med [Internet]. $2010 \mathrm{Jul} /$ Aug; [cited 2017 Jun 17]; 8(4):348-53. Available from: https://www.ncbi.nlm. nih.gov/pubmed/20644190. DOI: 10.1370/afm.1139

19. Machado MH, Aguiar Filho W, Lacerda WF, Oliveira E, Lemos W Wermelinger $\mathrm{M}$, et al. General characteristics of nursing: the sociodemographic profile. Enferm Foco [Internet]. 2016 Feb; [cited 2017 Jun 17]; 7(no.esp):9-14. Available from: http://pesquisa.bvsalud.org/cvsp/ resource/en/bde-28479.DOI: 10.21675/2357-707X.2016.v7.nESP.686

20. Darbro N, Malliarakis KD. Substance abuse: risks factors and protective factors. J Nurs Regul [Internet]. 2012 Apr; [cited 2017 Jun 17]; 3(1):44-8. Available from: http://www.journalofnursingregulation. com/article/S2155-8256(15)30234-9/fulltext. DOI: 10.1016/S21558256(15)30234-9

21. Formiga MB, Vasconcelos SC, Galdino MKC, Lima MDC. Presence of dual diagnosis between users and non-users of licit and illicit drugs in Brazil. J Bras Psiquiatr [Internet]. 2015 Oct/Dec; [cited 2017 Jun 17]; 64(4):288-95. Available from: http://www.scielo.br/scielo. php? script $=$ sci arttext $\&$ pid $=S 0047-20852015000400288$. DOI; 10.1590/0047-208500000009122

22. Cavariani MB, Oliveira JB, Kerr-Corrêa F, Lima MCP. Positive expectations towards alcohol use and binge drinking: gender differences in a study from the GENACIS project, São Paulo, Brazil. Cad Saúde Pública [Internet]. 2012 Jul; [cited 2017 Jun 17]; 28(7):1394404. Available from: http://www.scielo.br/scielo.php?script=sci arttext\&pid=S0102-311X2012000700017\&lng=en. DOI: 10.1590/ S0102-311X2012000700017

23. Fachini A, Furtado EF. Gender differences in alcohol expectancies. Rev Psiquiatr Clín [Internet]. 2012; [cited 2017 Jun 17]; 39(2):6873. Available from: http://www.scielo.br/scielo.php?script=sci arttext\&pid=S0101-60832012000200005\&lng=en. DOI: $10.1590 /$ S0101-60832012000200005.

24. Kunyk D. Substance use disorders among registered nurses: prevalence, risks and perceptions in a disciplinary jurisdiction. J Nurs Manag [Internet]. 2015 Jan; [cited 2017 Jun 17]; 23(1):54-64. Available from: https://www.ncbi.nlm.nih.gov/pubmed/23952722. DOI:10.1111/ jonm. 12081

25. Volkow ND, Baler RD, Compton WM, Weiss SR. Adverse health effects of marijuana use. N Engl J Med [Internet]. 2014 Jun; [cited 2017 Jun 17]; 370(23):2219-27. Available from: https://www.ncbi.nlm.nih.gov/pu $\mathrm{bmed} /$ ?term $=$ Volkow+ND\%2C+Baler+RD\%2C+Compton+WM\%2C+ Weiss+SR.+Adverse+health+effects+of+marijuana+use.+N+Engl+J+ Med. DOI: 10.1056/NEJMra1402309

26. Picolotto E, Libardoni LFC, Migott AMB, Geib LTC. Prevalence and factors associated with psychoactives substances consumption for academics of nursing of the University of Passo Fundo. Ciênc Saúde Coletiva [Internet]. 2010 May; [cited 2017 Jun 17]; 15(3):64554. Available from: http://www.scielo.br/scielo.php?script=sci arttext\&pid=S1413-81232010000300006\&lng=en. DOI: $10.1590 /$ S1413-81232010000300006

27. Mahalik JR, Lombardi CM, Sims J, Coley RL, Lynch AD. Gender, maletypicality, and social norms predicting adolescent alcohol intoxication and marijuana use. Soc Sci Med [Internet]. 2015 Oct; [cited 2017 Jun 17];143:71-80. Available from: https://www.ncbi.nlm.nih.gov/ pubmed/26344125. DOI: 10.1016/j.socscimed.2015.08.013

28. Buu A, Dabrowska A, Heinze JE, Hsieh HF, Zimmerman MA. Gender differences in the developmental trajectories of multiple substance use and the effect of nicotine and marijuana use on heavy drinking in a high-risk sample. Addict Behav [Internet]. 2015 Nov; [cited 2017 Jun 17]; 50:6-12. Available from: https://www.ncbi.nlm.nih.gov/ pubmed/26093058. DOI: 10.1016/j.socscimed.2015.08.013 
29. Epstein PM, Burns $C$, Conlon HA. Substance abuse among registered nurses. AAOHN J [Internet]. 2010 Dec; [cited 2017 Feb 17]; 58(12):513-6. Available from: https://www.ncbi.nlm.nih.gov/pubmed/21188795

30. Rios KA, Barbosa DA, Belasco AGS. Evaluation of quality of life and depression in nursing technicians and nursing assistants. Rev Latino Am Enferm [Internet]. 2010 May/Jun; [cited 2017 Jun 17]; 18(3):41320. Available from: http://www.scielo.br/scielo.php?script=sci_ar ttext\&pid=S0104-11692010000300017. DOI: 10.1590/S010411692010000300017

31. Perry L, Lamont S, Brunero S, Gallagher R, Duffield C. The mental health of nurses in acute teaching hospital settings: a cross-sectional survey. BMC Nurs [Internet]. 2015 Mar; [cited 2017 Jun 17]; 27:14-5. Avaliable from: https://bmcnurs.biomedcentral.com/articles/10.1186/ s12912-015-0068-8. DOI: 10.1186/s12912-015-0068-8

32. Gong Y, Han T, Chen W, Dib HH, Yang G, Zhuang R, et al. Prevalence of anxiety and depressive symptoms and related risk factors among physicians in China: a cross-sectional study. PLoS One [Internet]. 2014 Jul; [cited 2017 Jun 17]; 9(7):e103242. Available from: https://www. ncbi.nlm.nih.gov/pmc/articles/PMC4106870/. DOI: 10.1371/journal. pone.0103242

33. Yazdanshenas Ghazwin M, Kavian M, Ahmadloo M, Jarchi A, Golchin Javadi $S$, Latifi $S$, et al. The association between life satisfaction and the extent of depression, anxiety and stress among Iranian nurses: a multicenter survey. Iran J Psychiatry [Internet]. 2016 Apr; [cited 2017 Jun 17]; 11(2):120-7. Available from: https://www.ncbi.nlm.nih.gov/pmc/ articles/PMC4947220/

34. Altemus M, Sarvaiya N, Neill Epperson C. Gender differences in anxiety and depression clinical perspectives. Front Neuroendocrinol [Internet]. 2014 Aug; [cited 2017 Jun 17]; 35(3):320-30. Available from: https://www. ncbi.nlm.nih.gov/pubmed/24887405. DOI: 10.1016/j.yfrne.2014.05.004
35. Elias MA, Navarro VL. The relation between work, health and living conditions: negativity and positivity in nursing work at a teaching hospital. Rev Latino Am Enferm [Internet]. 2006 Jul/Aug; [cited 2017 Jun 17]; 14(4):517-25. Available from: http://www.scielo.br/scielo. php?script=sci_arttext\&pid=S0104-11692006000400008\&lng=en. DOI 10.1590/S0104-11692006000400008

36. Santana LL, Sarquis LMM, Brev C, Miranda FMD, Felli VEA Absenteeism due to mental disorders in health professionals at a hospital in southern Brazil. Rev Gaúcha Enferm [Internet]. 2016 Apr [cited 2017 Jun 17]; 37(1):e53485. Available from: http://www.scielo.br/ scielo.php?script=sci_arttext\&pid=S1983-14472016000100416. DOI: 10.1590/1983-1447.2016.01.53485

37. Vieira TG, Beck CLC, Dissen CM, Camponogara S, Gobatto M, Coelho APF. Iness and the use of psychoative drugs workers at intensive care units. Rev Enferm UFSM [Internet]. 2013 May/Aug; [cited 2017 Jun 17] 3(2):205-14. Available from: https://periodicos.ufsm.br/reufsm/article/ view/7538. DOI: http://dx.doi.org/10.5902/217976927538

38. Bozimowski G, Groh C, Rouen P, Dosch M. The prevalence and patterns of substance abuse among nurse anesthesia students. AANA $\mathrm{J}$ [Internet]. 2014 Aug; [cited 2017 Jun 17]; 82(4):277-83. Available from: https://www.ncbi.nlm.nih.gov/pubmed/25167607

39. Vieira GCG, De Brida RL, Macuch RS, Massuda EM, Preza GP. Psychotropic use by nurses: relationship with work. Cinergis [Internet] $2016 \mathrm{Jul} / \mathrm{Sep}$; [cited 2017 Jun 17]; 17(3):191-5. Available from https://online.unisc.br/seer/index.php/cinergis/article/view/8118. DOI 10.17058/cinergis.v17i3.8118

40. Cotto JH, Davis E, Dowling GJ, Elcano JC, Staton AB, Weiss SR Gender effects on drug use, abuse, and dependence: a special analysis of results from the national survey on drug use and health. Gend Med [Internet]. 2010 Oct; [cited 2017 Jun 17]; 7(5):402-13. Available from: https://www.ncbi.nlm.nih.gov/pubmed/21056867. DOI: 10.1016/j. genm.2010.09.004 